Título artículo / Títol article:
Comparison of Simple and Rapid Extraction Procedures for the Determination of Pesticide Residues in Fruit Juices by Fast Gas Chromatography-Mass Spectrometry

Autores / Autors

Laura Cherta, Joaquim Beltran, Elena Pitarch, Félix Hernández

Revista:

Food Analytical Methods

Versión / Versió:

Versió pre-print

Cita bibliográfica / Cita bibliogràfica (ISO 690):

CHERTA, Laura, et al. Comparison of Simple and Rapid Extraction Procedures for the Determination of Pesticide Residues in Fruit Juices by Fast Gas Chromatography-Mass Spectrometry. Food Analytical Methods, 2013, vol. 6, no 6, p. 1671-1684.

url Repositori UJI: 


\title{
Comparison of simple and rapid extraction procedures for the determination of pesticide residues in fruit juices by fast gas-chromatography-mass spectrometry
}

\author{
Laura Cherta, Joaquim Beltran, Elena Pitarch, Félix Hernández \\ Research Institute for Pesticides and Water, University Jaume I, Castellón, Spain.
}

\begin{abstract}
Three sample treatment methods, based on QuEChERS, solid-phase extraction (SPE) and solid-phase microextraction (SPME), were compared and evaluated in order to obtain the best conditions to determine pesticide residues in fruit juice by fast gas chromatography-mass spectrometry (single quadrupole GC-MS). Analysis were performed under selected ion monitoring, acquiring the three most abundant and/or specific ions for each analyte and using their relative intensity ratios as a confirmatory parameter. The 3 methodologies (QuEChERS, SPE and SPME) were validated taking 15 selected pesticides as model compounds, using commercial apple juice. QuEChERS procedure was based on the AOAC Official Method 2007.01, using acetonitrile (containing $1 \%$ acetic acid) as extraction solvent and primary-secondary amine during the dispersive solid-phase extraction. Oasis hydrophilic-lipophilic balance cartridges were used for SPE, and polyacrylate fibers were used for direct immersion SPME procedure. Three isotopically labeled standards were added to the samples before extraction and used as surrogate standards. Validation parameters as recoveries, limits of detection, and limits of quantification (LOQ), as well as matrix effects and sample throughput, were obtained and compared for the three extraction procedures. QuEChERS was considered faster and led to the best quantitative results. In this way, validation was extended to up to 56 pesticides by applying QuEChERS in multi-fruit juice samples, obtaining LOQs ranging from 2 to $20 \mu \mathrm{g} / \mathrm{L}$ for most
\end{abstract}


compounds. Accuracy and precision were evaluated by means of recovery experiments at two concentration levels (10 and $100 \mu \mathrm{g} / \mathrm{L}$ ), obtaining recoveries between 70 and $120 \%$ in most cases and relative standard deviations below $15 \%$. Finally, the QuEChERS method was applied to the analysis of commercial juices, including mango-apple, pineapple, grapefruit and orange.

\section{Keywords}

QuEChERS; SPE; SPME; Pesticides; Fast gas chromatography-mass spectrometry; juices.

\section{INTRODUCTION}

Pesticide residues can remain in food after they are applied to crops, even after being washed, processed and prepared, and may result in adverse consequences to the human health. Their concentrations in processed food are usually lower than those observed in whole fruit due to their degradation through oxidative mechanisms or elimination during food processing, mainly after washing and peeling (Picó and Kozmutza 2007; Burchat et al. 1998; Patyal et al. 2004). The European Commission (2008) has set harmonized maximum residue levels (MRL) based on comprehensive assessment of the properties of the active substance and the residue behavior on treated crops. In most cases, no MRLs are set for processed food as juices. Then, the limit applied MRL applied for juice is the corresponding MRL for raw agricultural commodity, taking into account the concentration or dilution factor related to the manufacturing process (if available). Regulations and monitoring programs have to be adopted in order to strengthen food safety and control pesticide exposure to unacceptable levels in food. Analytical methodologies must be able to accurately determine the low concentration levels set up by the legislation. This is especially relevant for fruit and vegetable juices to have better knowledge of the pesticide levels actually present in this type of processed samples. 
As it is already well-known, chromatographic techniques coupled to mass spectrometry (MS) are the most powerful tools for the identification and quantification of pesticides and other contaminants in food. Gas chromatography (GC) coupled to MS with single quadrupole analyzer operating in selected ion monitoring (SIM) has been widely applied for the multiresidue analysis of GCamenable pesticides in different vegetable and fruit matrices (Mezcua et al. 2009; Mladenova and Shtereva 2009). The interest on reducing analysis time in multiresidue analysis has increased in the last years, looking for methods designed to determine as many compounds as possible in a short time. The use of fast GC allows rapid separations, satisfying current demands of higher sample throughput with not much sophisticated instrumentation (Dömötörová and Matisová 2008; Kirchner et al. 2005). However, determination of pesticide residues in food typically requires multiple steps: extraction, cleanup and subsequent determination by GC, in some cases after derivatization; thus, faster sample treatment methods are also desirable to reach high sample throughput.

When dealing with liquid samples, like juices, a classical technique for sample preparation is solid-phase extraction (SPE). A wide variety of sorbents and elution solvents can be used depending on the characteristics of the compounds to be extracted. $\mathrm{C}_{18}$ and Oasis hydrophilic-lipophilic balance (HLB) cartridges are among the most widely used in multiresidue methods (Marín et al. 2009; Xue et al. 2006; Piedra et al. 2000; Sabik et al. 2000; Picó et al. 2007; Cherta et al. 2012; Pitarch et al. 2007). Albero et al. (2005) developed a multiresidue method for the determination of pesticides using $10 \mathrm{ml}$ juice samples $\mathrm{C}_{18}$ cartridge. Pang et al. (2006) used graphitized carbon black SPE cartridges in order to extract pesticides from $15 \mathrm{~g}$ of fruit juice. An immunoaffinity-based SPE procedure has been also applied for the determination of triazines in fruit juices (Dallüge et al. 1999).

A fast and simple alternative for sample treatment is the QuEChERS procedure (Anastassiades et al. 2003), which has been widely and successfully applied for the determination of pesticide residues in fruits and vegetables. It has been subjected to several modifications based on authors' preferences, but the AOAC Official Method 
2007.01 (Lehotay et al. 2005) and the Standard Method EN 15662 (Payá et al. 2007) are the two official and most known versions. This methodology offers some advantages such as high sample throughput, high recoveries for a wide polarity and volatility range of pesticides and accurate results. QuEChERS combined with fast GC becomes a good choice to speed up multiresidue analysis. Although this procedure has been implemented for a wide range of commodities, especially fruits and vegetables in many routine laboratories with satisfactory results (Cieślik et al. 2011; Dai et al. 2011; Jiang et al. 2009; Kolberg et al. 2011; Park et al. 2011; Cherta et al. 2012a), only few publications have been reported for the analysis of juice samples, especially using GC or fast GC. The original QuEChERS version has been applied for the determination of 118 pesticides in vegetable juice by GC-MS and liquid chromatography-tandem mass spectrometry (Nguyen et al. 2009). Furlani et al. (2011) reported the determination of pesticide residues in sugarcane juice by GC with electron capture detection, also applying the unbuffered original QuEChERS version.

Another interesting approach for juice samples is the use of solid-phase microextraction (SPME), which has been successfully applied in pesticide residue analysis in water, soil, food, and biological samples (Beltran et al. 2000, 2001, 2003; Kataoka et al. 2000; Cervera et al. 2011; Fuster et al. 2005). SPME has gained in popularity since it minimizes sample preparation and also allows performing extraction and preconcentration in a single step. The most common approach for nonvolatile pesticides is the application of SPME by direct immersion (DI-SPME) (Fidalgo-Used et al. 2006; Farajzadeh and Hatami 2004; Natangelo et al. 2002; Simplício and Vilas Boas 1999), but its application to complex matrices is troublesome due to the absorption of interferences onto the fiber. This fact can be overcome if a previous solvent extraction is performed and the subsequent DI-SPME is applied over the separated aqueous extract (Kataoka et al. 2000; Zambonin et al. 2002) or by simply diluting the sample in order to simplify the matrix complexity (Sen et al. 1997). In the case of volatile compounds, the use of SPME in headspace mode (Hernández et al. 2002; López et al. 2001; Schurek et al. 2008; Serrano et al. 2009) allows minimizing the matrix interferences. 
The aim of this work has been to critically compare three sample treatment methods based on QuEChERS, SPME and SPE in order to evaluate their applicability for pesticide residue analysis in fruit juice samples. All methods have been validated using apple juice samples. Determination has been performed by fast GC-MS with single quadrupole working under the SIM mode.

\section{EXPERIMENTAL}

\section{Reagents and materials}

Pesticide standards used for this work were purchased from Dr. Ehrenstorfer (Augsburg, Germany). Stock standard solutions (nominal concentration, $500 \mu \mathrm{g} / \mathrm{ml}$ ) were prepared by dissolving reference standards in acetone and were stored in a freezer at $-20^{\circ} \mathrm{C}$. Working standard mixtures for sample fortification were prepared by dilution of stock solutions in acetonitrile (for QuEChERS) and in acetone (for SPME and SPE).

Three isotopically labeled internal standards (ILIS) were used as surrogates: $p, p^{\prime}-$ DDE$-\mathrm{D}_{8}, \quad$ terbuthylazine- $\mathrm{D}_{5} \quad$ (Dr. Ehrenstorfer) and hexachlorobenzene (HCB)-13 $\mathrm{C}_{6}$ (Cambridge Isotope Labs Inc., Andover, MA, USA). A working mixed solution of labeled standards was prepared by volume dilution of individual stock solutions with acetonitrile $(\mathrm{MeCN})$ and acetone and stored at $4{ }^{\circ} \mathrm{C}$.

Acetone, hexane, $\mathrm{MeCN}$, dichloromethane (DCM), glacial acetic acid (HAc), anhydrous magnesium sulfate $\left(\mathrm{MgSO}_{4}\right)$, anhydrous sodium acetate $(\mathrm{NaAc})$ and sodium chloride $(\mathrm{NaCl})$ were purchased from Scharlab (Barcelona, Spain). All solvents were for pesticide residue analysis or high-performance liquid chromatography (HPLC) grade. Two types of $2 \mathrm{ml}$ microcentrifuge tubes for dispersive solid-phase extraction (d-SPE; used for the cleanup step) containing $50 \mathrm{mg}$ primary-secondary amine (PSA) and $150 \mathrm{mg}$ anhydrous $\mathrm{MgSO}_{4}$ or $50 \mathrm{mg} \mathrm{PSA}$, $150 \mathrm{mg}$ anhydrous $\mathrm{MgSO}_{4}$ and $50 \mathrm{mg} \mathrm{C}_{18}$ were obtained from Teknokroma (Barcelona, Spain). 
Oasis HLB cartridges (200 and $60 \mathrm{mg}$ ) were purchased from Waters (Milford, MA, USA) and Bond Elut cartridges $\mathrm{C}_{18}(500 \mathrm{mg}$ ) were obtained from Varian (Harbor City, CA, USA). SPME fibers of polydimethylsiloxane (PDMS, $100 \mu \mathrm{m}$ ), polyacrylate (PA, $85 \mu \mathrm{m}$ ), and divinylbenzene/carboxen/PDMS (DVB/CAR/PDMS, 50/30 $\mu \mathrm{m}$ ) were purchased from Supelco (Madrid, Spain).

\section{Sample material}

Apple and multi-fruit juice used for the validation study were purchased from a local market in Castellón (Spain). Once the optimum method was validated, four different juices were analyzed to investigate the presence of pesticides and test the applicability of the method. Apple-mango, pineapple and grapefruit juices were purchased from a local market in Castellón. Natural orange juice was obtained from fresh oranges collected from local harvesters.

\section{GC instrumentation}

Chromatographic measurements were performed on a GC system (Shimadzu QP2010 Plus) equipped with an autosampler (Shimadzu AOC-500o) and coupled to a single quadrupole mass spectrometer (GCMS-QP2010 Plus). Compounds were separated on a SAPIENS-5MS (Teknokroma) capillary column (length $20 \mathrm{~m} \times$ I.D. $0.10 \mathrm{~mm} \times$ film $0.10 \mu \mathrm{m})$.

For the chromatographic analysis of QuEChERS extracts (in MeCN), injections $(3 \mu \mathrm{l})$ were performed in programmable temperature vaporization (PTV) mode, which was programmed as follows: $40{ }^{\circ} \mathrm{C}$ (hold time, $0.5 \mathrm{~min}$ ), maintaining the split valve open; once the valve was closed, a rate of $400{ }^{\circ} \mathrm{C} / \mathrm{min}$ to $320^{\circ} \mathrm{C}$ (hold time, $0.5 \mathrm{~min}$ ) was applied, resulting in an injection total time of $1.70 \mathrm{~min}$. During this time, initial oven temperature was maintained at $60^{\circ} \mathrm{C}$ and then heated at a rate of $90{ }^{\circ} \mathrm{C} / \mathrm{min}$ to $225^{\circ} \mathrm{C}$, then $15{ }^{\circ} \mathrm{C} / \mathrm{min}$ to $270{ }^{\circ} \mathrm{C}$, and finally $150{ }^{\circ} \mathrm{C} / \mathrm{min}$ to $330^{\circ} \mathrm{C}$ (2 min), resulting in a total analysis time of $8.93 \mathrm{~min}$. Helium was used as carrier gas at a flow of $0.77 \mathrm{ml} / \mathrm{min}$ (corresponding to a linear velocity of $39.1 \mathrm{~cm} / \mathrm{s}$ ). 
When SPME was performed, the injector was operated in splitless mode at $280^{\circ} \mathrm{C}$ and the splitless time was $5 \mathrm{~min}$. During this time, initial column oven temperature was maintained at $50{ }^{\circ} \mathrm{C}$ and then programmed as previously indicated. In this case, the total analysis time was $12.14 \mathrm{~min}$.

The injector was also operated in splitless mode $(1 \mu \mathrm{l})$ when SPE extracts were analyzed, although injection temperature was $320{ }^{\circ} \mathrm{C}$, initial column temperature was $80^{\circ} \mathrm{C}$ and splitless time was $1.2 \mathrm{~min}$, so chromatographic run time was $8.01 \mathrm{~min}$.

The mass spectrometer was operated in the electron ionization mode $(70 \mathrm{eV})$. The source and the interface (transfer line) temperatures were adjusted to 225 and $300{ }^{\circ} \mathrm{C}$, respectively. The scan time in SIM mode was set at $0.1 \mathrm{~s}$. In SIM mode, the three most abundant and/or characteristic ions for each analyte were selected as target and reference ions. Solvent delay times of 3.5, 4 and $7 \mathrm{~min}$ for SPE, QuEChERS and SPME, respectively, were used to prevent damage to the filament of the ion source. Shimadzu software GCMSsolution was used to automatically process the data.

\section{Analytical procedures}

QUEChERS extraction: AOAC Official Method 2007.01 (Lehotay et al. 2005)

Fifteen milliliters of juice was poured in a 50-ml polypropylene centrifuge tube and $375 \mu \mathrm{l}$ of surrogate standard solution mixture of $1 \mathrm{mg} / \mathrm{L}$ in $\mathrm{MeCN}$ was added and mixed on a vortex for $1 \mathrm{~min}$. Extraction was carried out using $15 \mathrm{ml} \mathrm{MeCN}$ (with $1 \%$ $\mathrm{HAc}$ ) and shaking by hand during $30 \mathrm{~s}$. Then, $6 \mathrm{~g}$ of anhydrous $\mathrm{MgSO}_{4}$ and $1.5 \mathrm{~g}$ of anhydrous NaAc were added and immediately shaken vigorously by hand to prevent the formation of $\mathrm{MgSO}_{4}$ agglomerates. Then, the tube was centrifuged at 3,000 rpm during 2 min.

For the cleanup step, $1 \mathrm{ml}$ of the upper MeCN extract was poured into the dSPE tubes containing $150 \mathrm{mg} \mathrm{MgSO}_{4}$ and $50 \mathrm{mg}$ PSA (in the case of orange juice samples, d-SPE tubes also contained $50 \mathrm{mg} \mathrm{C}_{18}$ ). The tubes were shaken on a vortex for $30 \mathrm{~s}$ and centrifuged at 3,000 rpm for $2 \mathrm{~min}$. The final MeCN supernatant extract 
was directly injected into the GC system under the experimental conditions indicated before (PTV mode).

Matrix-matched calibration was used for each sample matrix in order to be able to adequately quantify analytes in real samples. In this way, $500 \mu \mathrm{l}$ of $\mathrm{MeCN}$ extract obtained from a blank sample were mixed with $50 \mu$ of the pesticide standard solution in MeCN of adequate concentration, also containing the three ILIS. Each analyte was quantified by using relative responses (areas) to the corresponding internal standard.

\section{$>$ SPE extraction}

Twenty-five microliters of surrogate standard mixture in acetone of $1 \mathrm{mg} / \mathrm{L}$ was added to $1 \mathrm{ml}$ of juice sample and passed through the 200-mg $(6 \mathrm{ml})$ Oasis cartridge, previously conditioned by passing $6 \mathrm{ml}$ of methanol, $6 \mathrm{ml}$ of ethyl acetate/DCM, $6 \mathrm{ml}$ of methanol and $6 \mathrm{ml}$ of deionized water. After loading the sample, cartridges were washed with $6 \mathrm{ml}$ of deionized water and dried by passing air, using a vacuum for at least $30 \mathrm{~min}$. The retained analytes were eluted with $5 \mathrm{ml}$ ethyl acetate/DCM (50:50). The collected extract was evaporated, after the addition of $1 \mathrm{ml}$ hexane, under a gentle nitrogen stream at $40^{\circ} \mathrm{C}$ until $0.5 \mathrm{ml}$, adjusted to $1 \mathrm{ml}$ with hexane and injected into the GC system under the experimental conditions indicated before. Quantification of analytes in samples was carried out from calibration curves prepared with standards in solvent, using relative responses of each compound to the corresponding ILIS.

\section{$>$ SPME extraction}

Extraction of juice samples was performed by direct immersion of a PA fiber into the sample, under magnetic stirring $(600 \mathrm{rpm})$ for $30 \mathrm{~min}$. Samples were prepared by adding $25 \mu$ of surrogate mixture $(200 \mathrm{ng} / \mathrm{ml})$ in acetone to $0.5 \mathrm{ml}$ of juice and subsequent dilution with $1.5 \mathrm{ml}$ of deionized water in a septum-capped 4-ml clear glass vial. Desorption of the fiber was carried out at $280^{\circ} \mathrm{C}$ for $5 \mathrm{~min}$ in the splitless injector. 
Quantification of analytes in samples was carried out using calibration curves prepared by spiking $2 \mathrm{ml}$ of deionized water with $25 \mu \mathrm{l}$ of pesticide standard solution of adequate concentration and $25 \mu \mathrm{l}$ of surrogate mixture, both in acetone, and extracting these samples under the SPME procedure previously indicated. Relative responses of each compound to the corresponding internal standard were used.

\section{Validation study}

The three extraction methods used were validated using commercial apple juice samples in terms of linearity, accuracy, precision, limits of quantification (LOQ) and limits of detection (LOD). Confirmation capability of the method for positive samples was also evaluated.

Linearity was studied using calibration standards injected by triplicate. It was considered linear when regression coefficient was higher than 0.99 and the residuals lower than $30 \%$ without any clear tendency.

Accuracy was estimated from recovery experiments at two concentration levels (10 and $100 \mu \mathrm{g} / \mathrm{L}$ for QUEChERS and SPE; 1 and $10 \mu \mathrm{g} / \mathrm{L}$ for SPME) $(n=6)$. Precision was expressed as repeatability (intraday precision) in terms of relative standard deviation (RSD, in precent) ( $n=6)$ at each fortification level.

LOQ was estimated as the analyte concentration that produced a peak signal ten times that of the background noise and it was calculated using the chromatograms at the lowest fortification level tested with satisfactory recovery (70$120 \%$ ) and precision (RSD <20 \%). LOD was estimated in the same way, but for a signal-to-noise ratio of 3 .

In order to confirm peak identity in samples, the ratio between the quantification ion (target, $Q$ ) and the reference ions ( $q i)$ was evaluated and compared with the theoretical value obtained from reference standard solutions. The confirmation criterion was based on the European Commission Decision 2002/657/EC (European Commission Decision 2002), which establishes the maximum tolerances for $Q / q$ ratio deviation from theoretical values as a function of 
relative intensities. Coincidence between the retention time in a sample and the corresponding standard was also required to confirm a positive finding (maximum deviation, $\pm 0.5 \%)$.

\section{RESULTS AND DISCUSSION}

In a first step, for the optimization and comparison of extraction procedures, 15 selected pesticides (from a total of 56 pesticides studied in this work) were used (Table 1). Three sample treatments (QuEChERS, SPE and SPME) were studied in order to evaluate their advantages and disadvantages using apple juice sample as model matrix sample. The QuEChERS procedure was not optimized as it was based on the AOAC Official Method and applied in the same conditions as in our previous work (Cherta et al. 2013). SPME and SPE were subjected to an optimization study.

Table 1. List of compounds studied in method optimization.

\begin{tabular}{|c|c|c|c|c|c|c|c|c|}
\hline \multirow{3}{*}{ Compound } & \multicolumn{2}{|c|}{ QUECHERS } & \multicolumn{2}{|r|}{ SPME } & \multicolumn{2}{|r|}{ SPE } & \multirow{2}{*}{\multicolumn{2}{|c|}{$\begin{array}{l}\text { Monitored ions in } \\
\text { SIM }\end{array}$}} \\
\hline & & Time window & & Time window & & Time window & & \\
\hline & $t_{R}(\min )$ & $\begin{array}{l}\text { (min) } \\
\text { (SIM group) }\end{array}$ & $\mathrm{t}_{\mathrm{R}}(\min )$ & $\begin{array}{l}\text { (min) } \\
\text { (SIM group) }\end{array}$ & $t_{R}(\min )$ & $\begin{array}{l}\text { (min) } \\
\text { (SIM group) }\end{array}$ & $\begin{array}{c}\text { Target } \\
\text { ion }\end{array}$ & $\begin{array}{l}\text { Reference } \\
\text { ions }\end{array}$ \\
\hline Trifluralin & 4.542 & $4 \cdot 30-4 \cdot 70$ & 7.931 & $7.80-8.05$ & 3.772 & $3.60-3.86$ & 264 & 290,306 \\
\hline Atrazine & 4.780 & $4.70-5.00$ & 8.156 & $8.05-8.40$ & 3.994 & $3.86-4.30$ & 200 & 202,215 \\
\hline Hexachlorobenzene- ${ }^{-13} \mathrm{C}_{6} *$ & 4.780 & & 8.172 & & 4.013 & & 292 & \\
\hline Hexachlorobenzene & 4.780 & & 8.173 & & 4.013 & & 284 & 282,286 \\
\hline Terbuthylazine- $\mathrm{D}_{5}{ }^{*}$ & 4.843 & & 8.219 & & 4.054 & & 219 & \\
\hline Terbuthylazine & 4.853 & & 8.229 & & 4.064 & & 214 & 173,229 \\
\hline Chlorpyriphos methyl & 5.214 & $5.00-5.40$ & 8.586 & $8.40-8.80$ & 4.423 & $4 \cdot 30-4.60$ & 286 & 125,288 \\
\hline Alachlor & 5.248 & & 8.618 & & 4.453 & & 160 & 132,188 \\
\hline Chlorpyrifos & $5 \cdot 508$ & $5.40-5.65$ & 8.868 & $8.80-9.10$ & 4.703 & $4.60-4.90$ & 314 & 197,199 \\
\hline Aldrin & $5 \cdot 566$ & & 8.937 & & 4.771 & & 263 & 101,261 \\
\hline Isodrin & 5.783 & $5.65-5.90$ & 9.148 & $9.10-9.35$ & 4.982 & $4.90-5.10$ & 193 & 195,263 \\
\hline Endosulfan I & 6.135 & $5 \cdot 90-6.19$ & 9.489 & $9.35-9.80$ & $5 \cdot 323$ & $5.10-5.61$ & 241 & 170,239 \\
\hline$p, p^{\prime}-\mathrm{DDE}-\mathrm{D}_{8}{ }^{*}$ & 6.240 & $6.19-6.45$ & 9.575 & & 5.413 & & 254 & \\
\hline$p, p^{\prime}-\mathrm{DDE}$ & 6.256 & & 9.591 & & 5.428 & & 246 & 248,318 \\
\hline Dieldrin & 6.348 & & 9.693 & & $5 \cdot 528$ & & 263 & 265,277 \\
\hline Endrin & 6.548 & $6.45-7.00$ & 9.889 & $9.80-10.20$ & 5.723 & $5.61-6.10$ & 263 & 261,345 \\
\hline Endosulfan II (a) & 6.626 & & 9.960 & & 5.796 & & 241 & 243,339 \\
\hline Bifenthrin & 7.227 & $7.00-7.30$ & 10.544 & $10.20-10.80$ & 6.389 & $6.10-6.50$ & 181 & 165,166 \\
\hline
\end{tabular}

* ILIS used in this work

(a) Target ion modified to 243 in QuEChERS extraction. 


\section{SPME optimization}

In order to establish the optimum conditions for the extraction of the selected pesticides in apple juice samples, several parameters of the SPME procedure (type of fiber, sample dilution, salt and solvent addition and extraction and desorption times) were considered separately. Extraction temperature was set at room temperature and magnetic stirring at $600 \mathrm{rpm}$.

Firstly, the selection of the fiber was carried out by testing three different fibers: PDMS, PA and DVB/CAR/PDMS, under the same SPME conditions and comparing the chromatographic responses obtained. Each fiber was immersed during $15 \mathrm{~min}$ into $0.5 \mathrm{ml}$ of juice spiked at $50 \mu \mathrm{g} / \mathrm{L}$ (diluted with $2.5 \mathrm{ml}$ of water) and desorbed into the $\mathrm{GC}$ at $280^{\circ} \mathrm{C}$ during $5 \mathrm{~min}$ (DVB/CAR/PDMS was desorbed at $270{ }^{\circ} \mathrm{C}$, according to the manufacturer's recommendation). The best results were obtained for the PA fiber, as shown in Fig. 1, so this fiber was used for further experiments.

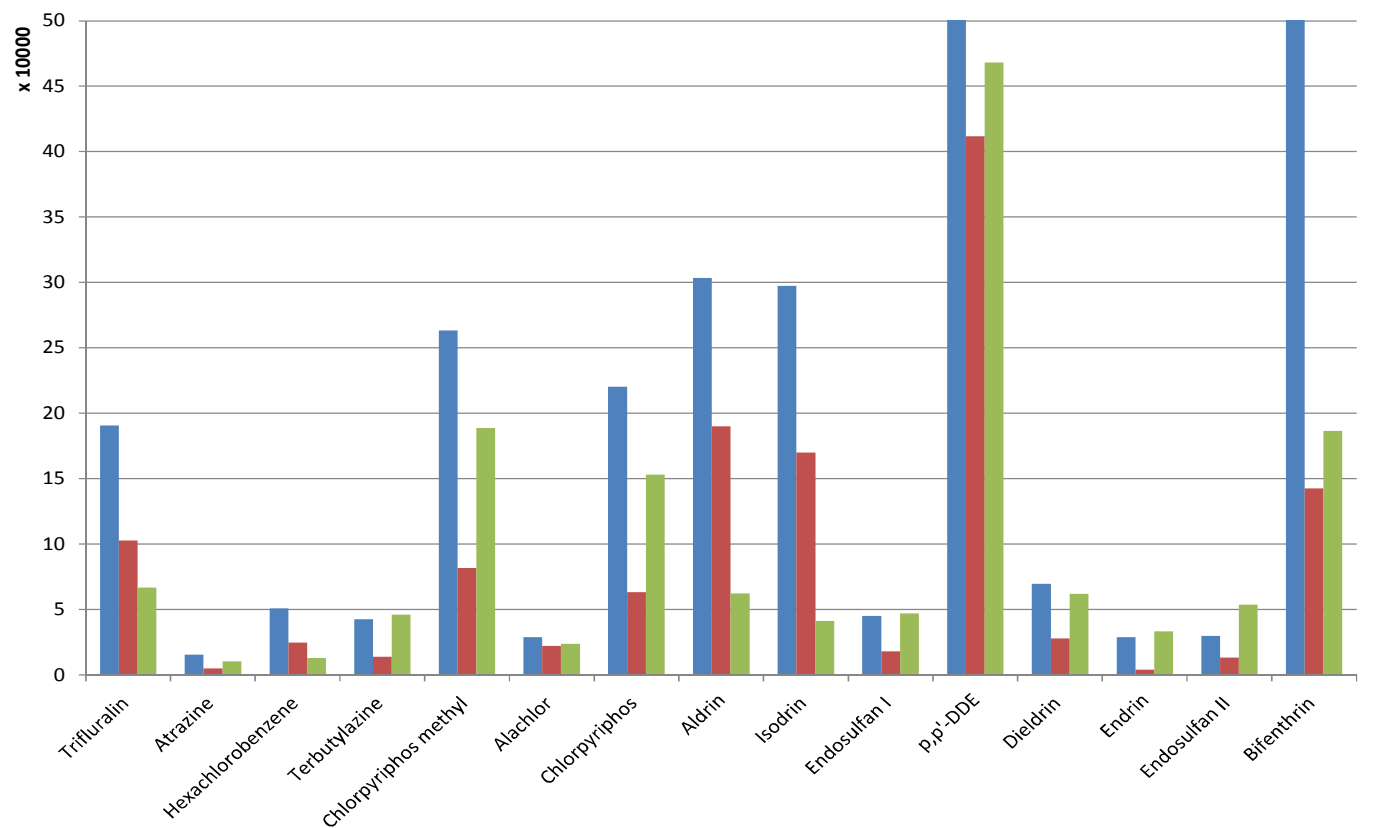

Fig. 1. Effect of SPME fiber type over extraction efficiency for selected pesticides ( $0.5 \mathrm{ml}$ of $50 \mu \mathrm{g} / \mathrm{L}$ spiked apple juice, diluted with $2.5 \mathrm{ml}$ of water; 15 min extraction). 
A statistical optimization procedure based on a full factorial experiment design was applied. It allowed not only determining the optimum values for the selected variables but also detecting interactions between variables or identifying which ones did not affect the response. Optimization was carried out in a two-step scheme: first, a two-level full factorial design was applied to detect significant variables and, then, a surface response design was applied to determine the optimum values for those significant variables.

Three variables (addition of hexane/acetone (1:1), salting-out effect, and sample dilution) were studied at two levels (o and $400 \mu \mathrm{l}$ for hexane, o and $20 \%$ for $\mathrm{NaCl}$, and 1.5 and $3.5 \mathrm{ml}$ for $\mathrm{H}_{2} \mathrm{O}$ ). A $2^{3}$ factorial design was performed, including 3 central points, so a total number of 11 randomized experiments were done. The statistical software package Statgraphics Centurion XV was used to generate the table of experiments and to evaluate the results obtained. The area of each pesticide was used as response function. The main effects of each variable and all the interactions were studied by means of the resulting Pareto charts. Fig. 2 illustrates an example of the corresponding Pareto chart obtained for HCB (as all compounds showed the same general trend).
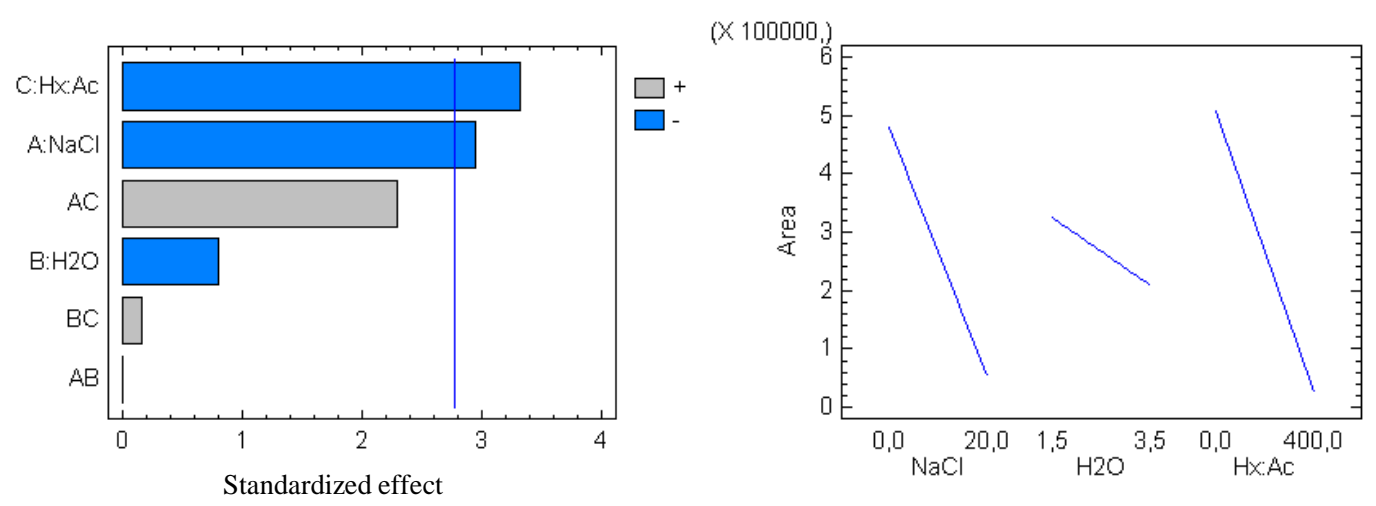

Fig. 2. Pareto chart of standardized effects of $2^{3}$ factorial design for HCB, using the peak area as the function response, and main effects plots. 
The length of the horizontal bar in the chart is proportional to the absolute value of the estimated effect; the vertical line defines the $95 \%$ confidence level. An effect is considered statistically significant if it exceeds this line. A general behavior was that solvent and salt addition presented a significant and negative effect, so both variables were selected for the next step in the optimization. As sample dilution was not significant but also had a negative effect, the lowest value tested, $1.5 \mathrm{ml}$, was selected. This minimum value was selected in order to have enough sample volume to cover the stationary phase of the SPME fiber and to have some matrix dilution effect that would improve quantification, as already described in the literature (Beltran et al. 2000).

Then, a $3^{2}$ factorial design, including three central points, was performed in order to study salt and solvent addition at three levels. Values for these variables were set at the same levels as in the first design. This case required 12 randomized experiments and the response function used again was the peak area for each compound. The response surface for HCB (Fig. 3) obtained from the results of these experiments shows the negative effect of adding salt and solvent since extraction efficiency decreases proportionally to the addition of $\mathrm{NaCl}$ and hexane/acetone.
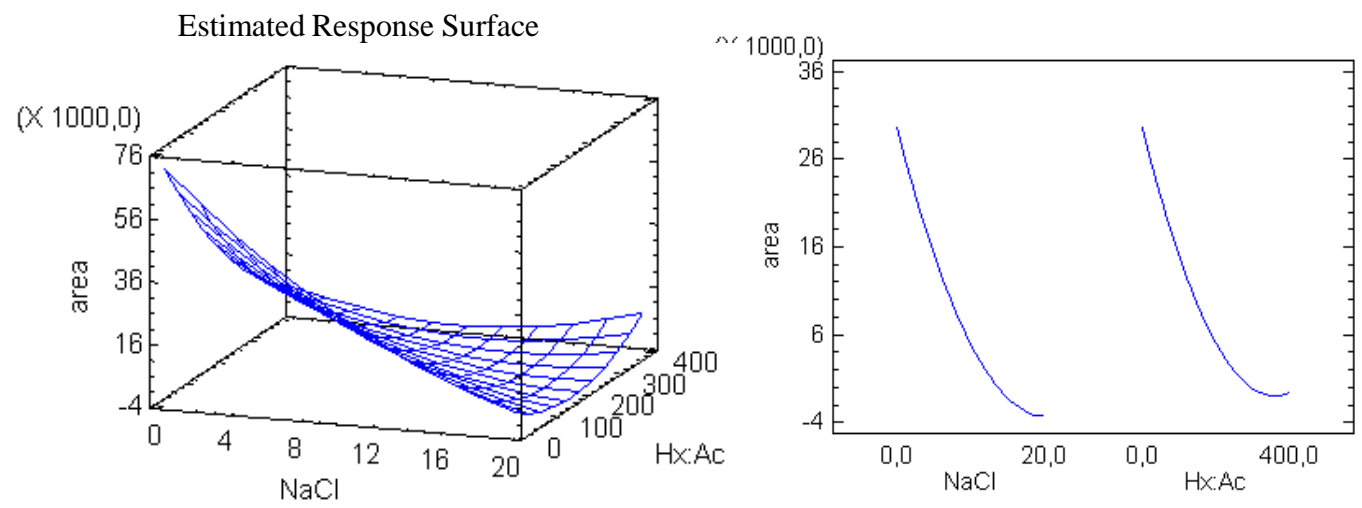

Fig. 3. Response surface obtained from a quadratic model for simultaneous optimization of salt and solvent addition, using the peak area as the function response, and main effects plots for HCB. 
Therefore, the optimal conditions were found to be without modifying ionic strength or adding solvent. The effect of $\mathrm{NaCl}$ (or other ionic salts) has been widely discussed and different behaviors have been reported. In most cases, the salting out effect tends to increase extraction efficiency (Beltran et al. 1998; Boyd-Boland and Pawliszyn 1995), but this effect also depends on the solubility and polarity of the analytes and sometimes a decrease in sensitivity is noticed when larger amounts of salt are added (Cortés-Aguado et al. 2008; Magdic et al. 1996). Moreover, at higher concentration levels, $\mathrm{NaCl}$ crystals can occupy some of the active fiber sites and thus decrease extraction recoveries (Farajzadeh and Hatami 2004).

Optimization of the absorption equilibrium was performed by extracting replicate samples at different times (from 10 to $120 \mathrm{~min}$ ). Analyte mass absorption, expressed as the peak area, was adjusted to a time-dependent equation given by $\mathrm{Ai}$ (1997):

$$
n=n_{\mathrm{o}}\left(1-e^{-a t}\right)
$$

where $n$ and $n_{\mathrm{o}}$ are the amounts of analyte absorbed at a time $t$ and at the equilibrium, respectively, and $a$ is a parameter that measures how fast the absorption equilibrium can be reached in the SPME process. Fig. 4 shows the results and the curves obtained after fitting the experimental data to the mentioned equation using the Statgraphics Centurion XV software for three of the studied compounds. Equilibrium time, estimated as the time necessary to extract $95 \%$ of $n_{0}$, was calculated for all the pesticides, giving values higher than $120 \mathrm{~min}$ in all cases. The feasibility of working in nonequilibrium conditions was considered, and thus, using the fitted equations, it was stated that establishing an extraction time of $30 \mathrm{~min}$ would lead to an extraction of around $50 \%$ with respect to the equilibrium situation for most compounds, and thus, analysis time would be considerably reduced. 

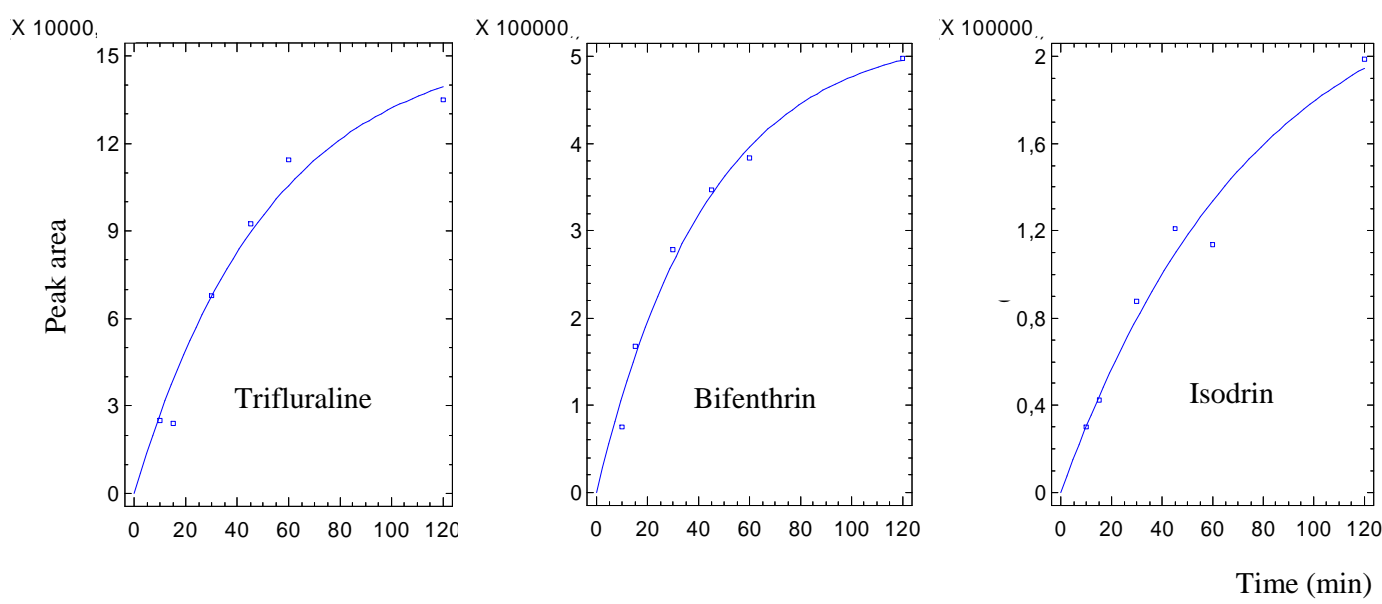

Fig. 4. SPME absorption time profiles for selected pesticides ( $0.5 \mathrm{ml}$ of $10 \mu \mathrm{g} / \mathrm{L}$ spiked apple juice, diluted with $2.5 \mathrm{ml}$ of water).

Finally, desorption time was studied in the range of 1-9 min under the optimum extraction conditions previously indicated. Peak areas increased with longer desorption times until complete desorption was reached, at about $5 \mathrm{~min}$ for most compounds. During this long desorption time, in order to profit from the effect of cold trapping, the oven temperature was maintained isothermal at $50^{\circ} \mathrm{C}$.

\section{SPE optimization}

SPE parameters as sorbent type, elution volume, elution solvent, volume of sample and evaporation step were optimized in order to find the optimum conditions for the extraction of the selected pesticides in juice samples.

As a first step, 200 and $60 \mathrm{mg}$ Oasis HLB cartridges and $500 \mathrm{mg}$ Bond Elut cartridges $\mathrm{C}_{18}$ were tested using $1 \mathrm{ml}$ of apple juice sample fortified with the 15 selected pesticides. Elution was carried out with $5 \mathrm{ml}$ of ethyl acetate/DCM. More consistent recoveries with lower RSD were obtained when $200 \mathrm{mg}$ Oasis HLB cartridges were used, so this sorbent was selected for further experiments.

Different solvents and mixtures of solvents were also studied to set the best elution conditions. Acetone, ethyl acetate, DCM and a mixture of ethyl acetate and 
DCM (50:50) were used to elute analytes retained in the cartridges at different volumes (from 2 to $10 \mathrm{ml}$ ). The elution using ethyl acetate/DCM mixture led to higher recoveries (although not still completely satisfactory), and $5 \mathrm{ml}$ was selected since poor recoveries were obtained using lower elution volumes and no significant differences were observed at higher volumes.

The evaporation step was carefully studied by evaluating the effect of evaporation until dryness. Poor recoveries were obtained when the SPE extract was evaporated until dryness and redissolved with hexane until $1 \mathrm{ml}$. Thus, the addition of $1 \mathrm{ml}$ hexane before the evaporation was considered; in this case, the extract was evaporated until $0.5 \mathrm{ml}$ and then adjusted to $1 \mathrm{ml}$ with hexane, avoiding possible losses of analytes during the evaporation process.

Different volumes of sample were tested in order to evaluate the maximum amount of sample to be passed through the cartridge without affecting the retention of the analytes. One milliliter of apple juice fortified at $100 \mu \mathrm{g} / \mathrm{L}, 10 \mathrm{ml}$ fortified at $10 \mu \mathrm{g} / \mathrm{L}$ and $100 \mathrm{ml}$ fortified at $1 \mu \mathrm{g} / \mathrm{L}$ were loaded to the cartridge and the signal intensity was evaluated. No chromatographic peaks were observed when using $100 \mathrm{ml}$, since the cartridge was overloaded with matrix components, impeding the retention of the analytes. The use of $10 \mathrm{ml}$ also had a negative effect on the chromatographic signal since a loss of $75 \%$ with respect to the use of $1 \mathrm{ml}$ was observed. Therefore, $1 \mathrm{ml}$ of sample volume was selected, achieving satisfactory sensitivity and maintaining the high speed of sample preparation.

\section{Comparison of analytical characteristics}

In order to critically compare the three extraction procedures, accuracy, precision, LOD and LOQ were evaluated using apple juice blank samples spiked with the 15 pesticides selected as model. Three ILIS were used as surrogates in order to correct possible losses of the analytes during the extraction process and/or instrumental deviations. Terbuthylazine- $\mathrm{D}_{5}$ was used as internal standard for herbicides, organophosphorus (OP) insecticides and pyrethroids; DDE- $\mathrm{D}_{8}$ was used 
for organochlorine pesticides and trifluralin; and $\mathrm{HCB}^{-13} \mathrm{C}_{6}$ was used for $\mathrm{HCB}$. The specific internal standard used for each individual compound is indicated in Table 2.

Linearity was studied in the range $1-500 \mu \mathrm{g} / \mathrm{L}(n=3)$ when QuEChERS and SPE were applied. In the case of SPME, the linearity was studied in the range 0.5$50 \mu \mathrm{g} / \mathrm{L}$, and fitting the experimental data to quadratic curves; this concentration range could not be extended to higher values due to the large signal intensity of most compounds that saturated the detector (although a wider range could be achieved by the dilution of the sample before the SPME). The regression coefficients were higher than 0.99 for all compounds over the whole range tested in the three methodologies and the residuals lower than $30 \%$.

As regards the matrix effects, the corresponding study for QuEChERS procedure was performed in our previous work (Cherta et al. 2013), concluding that matrix-matched calibration curves were necessary to compensate for matrix effects in quantitative applications. On the contrary, no severe matrix effects were observed when SPE was applied, so calibration curves prepared in solvent could be used in this case, being this an important advantage. In the SPME procedure, matrix effects were evaluated by comparison of chromatographic responses of spiked water ( $2 \mathrm{ml}$ ) and spiked juice samples ( $0.5 \mathrm{ml}$ juice and $1.5 \mathrm{ml}$ water), both extracted by SPME. No significant differences or signal enhancements were observed, probably due to the matrix dilution already considered in the development of the procedure. Then, calibration curves prepared in water and juice were analyzed, obtaining similar calibration slopes for most compounds, so calibration prepared in HPLC water could be used instead of matrix-matched calibration curves in the SPME procedure. 


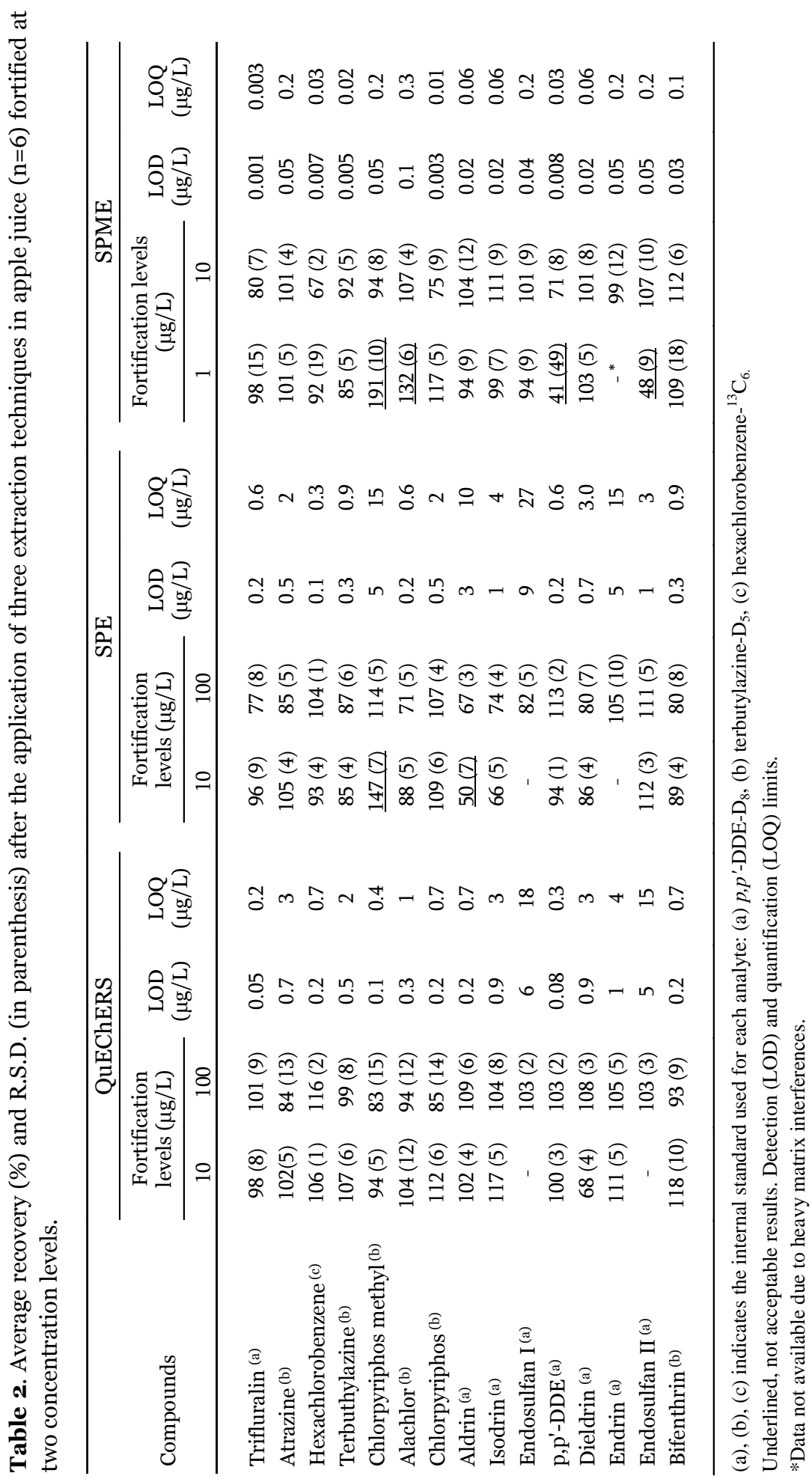


Accuracy and precision were evaluated by analyzing juice samples fortified at two concentrations $(n=6)$ of 10 and $100 \mu \mathrm{g} / \mathrm{L}$ for QuEChERS and SPE and 1 and $10 \mu \mathrm{g} / \mathrm{L}$ for SPME. Recoveries and RSD obtained for each analyte were calculated. As shown in Table 2, satisfactory recoveries (between 70 and $120 \%$ ) were obtained for all compounds at both spiking levels for the QuEChERS procedure, as well as adequate RSD values (lower than $15 \%$ ). Only two analytes, endosulfan I and II, could not be quantified at the lowest level due to poor sensitivity. LOQs ranged from 0.2 to $4 \mu \mathrm{g} / \mathrm{L}$, except for endosulfan I and II (around $15 \mu \mathrm{g} / \mathrm{L}$ ). Similar results were obtained for SPE, with the exceptions of chlorpyrifos methyl and aldrin, whose LOQs were slightly higher due to the inadequate recoveries presented at the lowest level. Endosulfan I and endrin could not be quantified at $10 \mu \mathrm{g} / \mathrm{L}$, but satisfactory recoveries were obtained at the highest fortification level. The LOQs achieved with both methodologies are in agreement to those previously obtained by other authors for pesticides in fruit juices (Albero et al. 2005). On the other hand, the application of SPME led to an important gain in sensitivity, which can be appreciated in Fig. $\mathbf{5}$, reaching lower LOQs than those obtained in the other extraction methods (even 200 times lower for some compounds). This behavior was also reported in the literature for OP pesticides (Beltran et al. 1998), but in general terms, LODs obtained for pesticide residues ranges from 0.1 to $10 \mu \mathrm{g} / \mathrm{L}$ (Hernández et al. 2002; López et al. 2001; Cortés-Aguado et al. 2008), so an important enhancement of sensitivity is achieved under conditions used in this work. However, five compounds presented inadequate recoveries at the lowest level, although they could be validated at $10 \mu \mathrm{g} / \mathrm{L}$. LOQs obtained for QuEChERS and SPE could not reach the nanograms per liter level, but were low enough for regulations purposes, considering that MRLs are commonly set at $10 \mu \mathrm{g} / \mathrm{L}$ in food commodities. 
a)

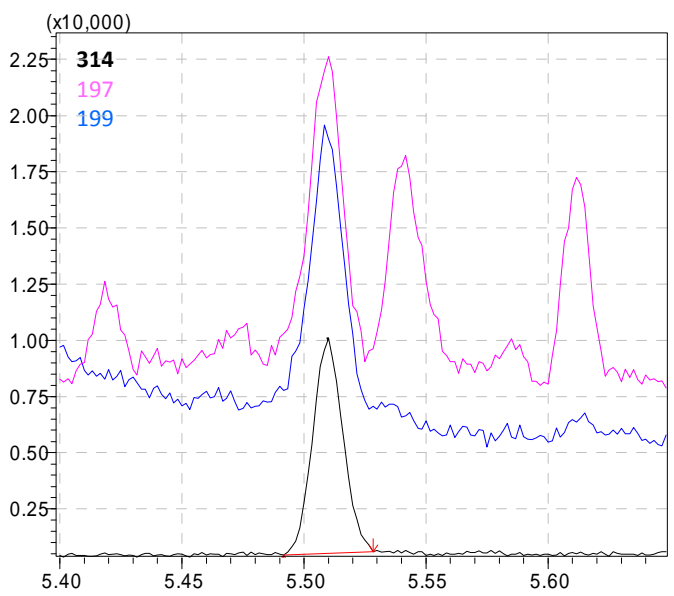

b)

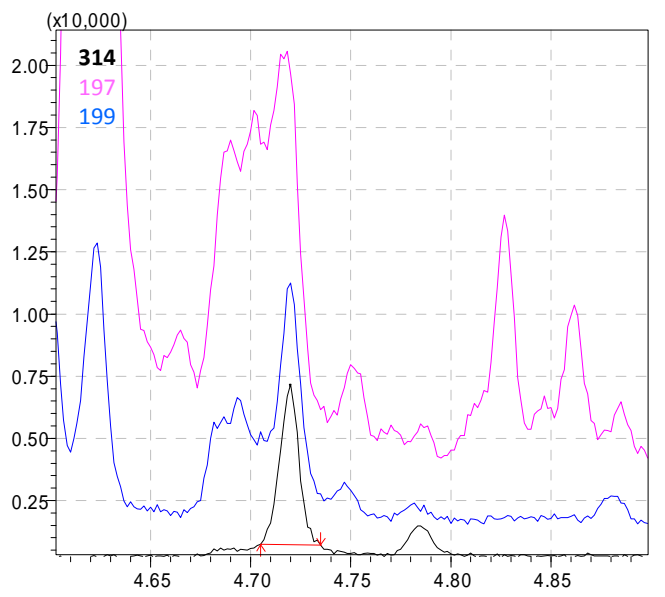

c)

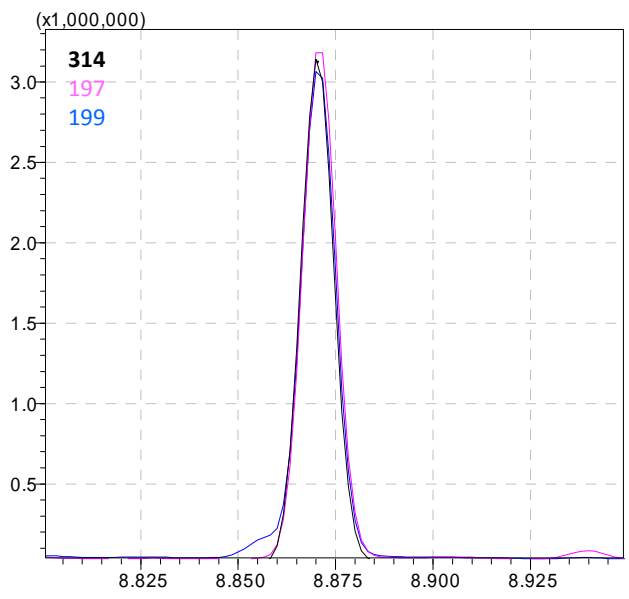

Fig 5. Comparison of chromatographic responses for chlorpyrifos in apple juice extract spiked at $0.01 \mathrm{mg} / \mathrm{L}$ after applying a QuEChERS, b SPE, and c SPME. Target ion (bold) and two reference ions are shown.

As regards the confirmation of positive samples, the guidelines of the European Commission Decision (2002) establish that, after the acquisition of three ions (target $(Q)$ and two reference ions $(q i)$ ), the comparison of the two $Q / q$ ratios measured in samples with those measured from reference standards shall lie within the maximum permitted tolerances. However, the expected $Q / q$ ratios can be altered mainly due to matrix interferences. This is specially noticed at low concentration levels owing to the 
lower abundance of the ions. In this work, we applied a more realistic criterion for the three methodologies: at the retention time of the analyte, three ions (target and reference) have to be observed in the sample and at least one $Q / q$ ratio has to be accomplished.

It is noteworthy that differences on $Q / q$ ratio accomplishment were observed depending on the extraction procedure applied. A higher number of compounds did not get ion ratios within the permitted tolerances after applying the SPE procedure. This seemed to be related to the fact that a higher number of reference ions were interfered by matrix coeluting components when SPE was applied, as illustrated in Fig. 5 in the case of chlorpyrifos. Better results of $Q / q$ ratio accomplishment were obtained for the QuEChERS procedure, surely due to the cleanup step included in the procedure. Thus, QuEChERS seemed to be a more adequate sample treatment for complex matrices than SPE. In the case of SPME, the higher sensitivity favored the compliance of $Q / q$ ratios similar to QuEChERS, so it can be concluded that SPE is not a good enough extraction method for juice samples.

Extraction time was also evaluated, considering that the analysis method was based on fast GC. SPME involved a longer extraction time since samples were extracted one by one (30 min of extraction for sample), so it reduced dramatically the sample throughput. Decreasing the extraction time to a value similar to that of the chromatographic run (maximizing sample throughput) would lead to lower extraction efficiency (around $20 \%$ with respect to the equilibrium situation for most compounds). Moreover, this technique requires an additional desorption time once injected into the GC, so it resulted in longer chromatographic time (10.8 min). QuEChERS is considered as a rapid method and less labor-consuming; around 10 samples can be extracted in approximately $2 \mathrm{~h}$. Moreover, shorter chromatographic time was possible after applying QuEChERS extraction (chromatographic time was around 9 min), taking more benefit from the fast GC.

In summary, the main advantage of SPME was the null solvent consumption and the possibility of reaching very low LOQs. However, the poor reproducibility of SPME specially noticed at low levels complicated the performance of the calibration 
curves and the subsequent quantification process. As regards QuEChERS, it was the faster extraction procedure, fitting well with fast GC, and led to more satisfactory quantification results. Therefore, QuEChERS was selected for further validation of a wider list of pesticides, included in Table 3 .

Table 3. Fast GC-MS conditions for 56 pesticides studied in the QuEChERS extraction applied to multi-fruit juice.

\begin{tabular}{|c|c|c|c|c|c|}
\hline \multirow[b]{2}{*}{ Compound } & \multirow[b]{2}{*}{$\mathrm{t}_{\mathrm{R}}(\min )$} & \multirow{2}{*}{$\begin{array}{l}\text { Window } \\
\text { (min) }\end{array}$} & \multirow{2}{*}{$\begin{array}{l}\text { Scan time } \\
\text { (s) }\end{array}$} & \multicolumn{2}{|c|}{ Monitored ions in SIM } \\
\hline & & & & $\begin{array}{c}\text { Target } \\
\text { ion }\end{array}$ & $\begin{array}{l}\text { Reference } \\
\text { ions }\end{array}$ \\
\hline Dichlorvos & 3.735 & $3.60-3.80$ & 0.10 & 185 & 109,187 \\
\hline Chlorpropham & 4.520 & $3.80-4.61$ & 0.10 & 127 & 154,213 \\
\hline Trifluralin & 4.542 & & & 264 & 290,306 \\
\hline Phorate & 4.652 & $4.61-4.81$ & 0.13 & 260 & 121,231 \\
\hline alpha-HCH & 4.723 & & & 219 & 181,217 \\
\hline Atrazine & 4.780 & & & 200 & 202,215 \\
\hline Hexachlorobenzene- ${ }^{13} \mathrm{C}_{6}{ }^{*}$ & 4.780 & & & 292 & \\
\hline Hexachlorobenzene & 4.780 & & & 284 & 282,286 \\
\hline Terbuthylazine- $\mathrm{D}_{5} *$ & 4.843 & & & 219 & \\
\hline Terbuthylazine & 4.853 & $4.81-5.01$ & 0.13 & 214 & 173,229 \\
\hline beta-HCH & 4.880 & & & 181 & 217,219 \\
\hline Propyzamide & 4.882 & & & 173 & 175,255 \\
\hline Diazinon & 4.885 & & & 137 & 152,179 \\
\hline Lindane & 4.890 & & & 181 & 183,219 \\
\hline Pirimicarb & 5.038 & $5.01-5.27$ & 0.18 & 166 & 138,238 \\
\hline Chlorothalonil & 5.127 & & & 266 & 264,268 \\
\hline Metribuzin & 5.172 & & & 144 & 198,199 \\
\hline Chlorpyriphos methyl & 5.214 & & & 286 & 197, 288 \\
\hline Parathion methyl & 5.235 & & & 263 & 216,246 \\
\hline Alachlor & 5.248 & & & 160 & 132,188 \\
\hline Heptachlor & 5.311 & $5.27-5.47$ & 0.11 & 272 & 100,102 \\
\hline Pirimiphos methyl & 5.332 & & & 290 & 125,244 \\
\hline Fenitrothion & 5.388 & & & 109 & 260,277 \\
\hline Malathion & 5.400 & $5.47-5.67$ & 0.15 & 127 & 125,173 \\
\hline Fenthion & 5.502 & & & 245 & 279,280 \\
\hline Metholachlor & 5.505 & & & 162 & 146,238 \\
\hline Chlorpyriphos & 5.508 & & & 314 & 197, 199 \\
\hline Parathion ethyl & 5.566 & & & 291 & 139,155 \\
\hline Aldrin & 5.566 & $5.67-5.91$ & 0.18 & 263 & 101,261 \\
\hline Cyprodinil & 5.822 & & & 224 & 210,225 \\
\hline Pendimethalin & 5.736 & & & 252 & 162,192 \\
\hline Clofenvinphos & 5.780 & & & 267 & 269,323 \\
\hline Isodrin & 5.783 & & & 193 & 195,263 \\
\hline
\end{tabular}


Table 3 (continued).

\begin{tabular}{|c|c|c|c|c|c|}
\hline \multirow[b]{2}{*}{ Compound } & \multirow[b]{2}{*}{$\mathrm{t}_{\mathrm{R}}(\mathrm{min})$} & \multirow{2}{*}{$\begin{array}{l}\text { Window } \\
\text { (min) }\end{array}$} & \multirow{2}{*}{$\begin{array}{l}\text { Scan time } \\
\text { (s) }\end{array}$} & \multicolumn{2}{|c|}{ Monitored ions in SIM } \\
\hline & & & & $\begin{array}{c}\text { Target } \\
\text { ion }\end{array}$ & $\begin{array}{c}\text { Reference } \\
\text { ions }\end{array}$ \\
\hline Quinalphos & 5.838 & & & 146 & 156,157 \\
\hline Tolylfluanid & 5.843 & $5.91-6.20$ & 0.10 & 137 & 238,240 \\
\hline Methidathion & 5.985 & & & 145 & 93,125 \\
\hline trans-Chlordane & 6.011 & & & 375 & 371,373 \\
\hline Endosulfan I & 6.135 & & & 170 & 239,241 \\
\hline$p, p^{\prime}-\mathrm{DDE}-\mathrm{D}_{8} *$ & 6.240 & & & 254 & \\
\hline$p, p^{\prime}-\mathrm{DDE}$ & 6.256 & $6.20-6.50$ & 0.10 & 246 & 248,318 \\
\hline Buprofezin & 6.309 & & & 105 & 104,172 \\
\hline Dieldrin & 6.348 & & & 263 & 265,277 \\
\hline Endrin & 6.548 & $6.50-6.88$ & 0.15 & 263 & 261,345 \\
\hline Endosulfan II & 6.626 & & & 195 & 241,339 \\
\hline$p, p^{\prime}-\mathrm{DDD}$ & 6.631 & & & 165 & 176,199 \\
\hline Ethion & 6.633 & & & 125 & 153,384 \\
\hline Oxadixyl & 6.713 & & & 132 & 120,146 \\
\hline Propiconazole I & 6.915 & $6.88-7.18$ & 0.10 & 173 & 175,259 \\
\hline Propiconazole II & 6.640 & & & 173 & 175,259 \\
\hline $\mathrm{p}, \mathrm{p}$-DDT & 6.650 & & & 165 & 199, 212 \\
\hline Endosulfan sulfate & 6.952 & & & 272 & 227,274 \\
\hline Bifenthrin & 7.227 & $7.18-7.42$ & 0.10 & 181 & 165,166 \\
\hline Phosmet & 7.337 & & & 160 & 104,161 \\
\hline Methoxychlor & 7.338 & & & 227 & 212,228 \\
\hline Tetradifon & 7.470 & $7.42-7.65$ & 0.10 & 159 & 227, 229 \\
\hline Pyriproxyfen & 7.518 & & & 136 & 137,186 \\
\hline Fenarimol & 7.705 & $7.65-7.85$ & 0.10 & 139 & 219,251 \\
\hline Cypermethrin & 8.168 & $7.85-8.90$ & 0.10 & 163 & 127,181 \\
\hline Fenvalerate & 8.470 & & & 125 & 167,169 \\
\hline
\end{tabular}

* ILIS used in this work

\section{Validation for QuEChERS procedure for 56 pesticides}

A complete validation of QuEChERS was performed for 56 pesticides in multifruit juice. The three ILIS were again used as surrogates. The specific internal standard used for each compound is indicated in Table 4. 
Table 4. Average recovery (in percent) and RSD (in parenthesis) for multi-fruit juice after QuEChERS extraction and fast GC-MS analysis.

\begin{tabular}{|c|c|c|c|c|}
\hline \multirow{2}{*}{ Compounds } & \multicolumn{2}{|c|}{ Fortification levels $(\mu \mathrm{g} / \mathrm{L})$} & \multirow{2}{*}{$\begin{array}{c}\text { LOD } \\
(\mu \mathrm{g} / \mathrm{L})\end{array}$} & \multirow{2}{*}{$\begin{array}{c}\text { LOQ } \\
(\mu \mathrm{g} / \mathrm{L})\end{array}$} \\
\hline & 10 & 100 & & \\
\hline Dichlorvos (a) $^{\text {(a) }}$ & $96(10)$ & $86(11)$ & 0.6 & 2 \\
\hline Chlorpropham (a) & $103(12)$ & $90(10)$ & 0.6 & 2 \\
\hline Trifluralin ${ }^{(b)}$ & $95(13)$ & $105(7)$ & 0.3 & 0.9 \\
\hline Phorate $^{(a)}$ & $99(8)$ & $87(9)$ & 2 & 6 \\
\hline alpha-HCH $^{(b)}$ & $99(7)$ & $104(5)$ & 2 & 6 \\
\hline Atrazine $^{(a)}$ & - & $83(12)$ & 6 & 18 \\
\hline Hexachlorobenzene ${ }^{(c)}$ & $92(5)$ & $113(3)$ & 0.3 & 0.9 \\
\hline Terbuthylazine (a) & $109(6)$ & $95(7)$ & 2 & 6 \\
\hline beta-HCH ${ }^{(b)}$ & $88(8)$ & $87(7)$ & 2 & 6 \\
\hline Propyzamide (a) & - & $100(5)$ & 7 & 21 \\
\hline $\operatorname{Diazinon}^{(\mathrm{a})}$ & $112(6)$ & $86(8)$ & 3 & 10 \\
\hline Lindane $^{(\mathrm{b})}$ & $91(9)$ & $83(8)$ & 2 & 6 \\
\hline Pirimicarb (a) & $104(8)$ & $82(7)$ & 2 & 6 \\
\hline Chlorothalonil (c) & - & - & - & - \\
\hline Metribuzin (a) & - & $86(14)$ & 12 & 36 \\
\hline Chlorpyriphos methyl (a) & $91(9)$ & $81(12)$ & 0.3 & 0.9 \\
\hline Parathion methyl (a) & - & - & - & - \\
\hline Alachlor $^{(a)}$ & $96(10)$ & $88(15)$ & 1 & 3 \\
\hline Heptachlor $^{(b)}$ & $68(14)$ & $98(9)$ & 2 & 6 \\
\hline Pirimiphos methyl (a) & $120(4)$ & $111(8)$ & 2 & 6 \\
\hline Fenitrothion (a) & - & - & - & - \\
\hline Malathion $^{\text {(a) }}$ & - & $80(11)$ & 4 & 12 \\
\hline Fenthion (a) & - & $109(8)$ & 10 & 30 \\
\hline Metholachlor (a) & $105(3)$ & $88(13)$ & 0.7 & 2 \\
\hline Chlorpyriphos (a) & $119(7)$ & $104(7)$ & 0.9 & 3 \\
\hline Parathion ethyl (a) & - & - & - & - \\
\hline Aldrin (b) & $110(6)$ & $85(6)$ & 2 & 6 \\
\hline Cyprodinil (c) & - & - & - & - \\
\hline Pendimethalin (a) & - & $95(6)$ & 8 & 24 \\
\hline Chlofenvinphos (a) & - & $105(10)$ & 9 & 27 \\
\hline Isodrin (b) & $76(15)$ & $78(10)$ & 2 & 6 \\
\hline Quinalphos (a) & - & $92(9)$ & 6 & 18 \\
\hline Tolylfluanid (c) & - & - & - & - \\
\hline Methidathion (a) & i. & i. & - & - \\
\hline trans-Chlordane $^{(b)}$ & $78(12)$ & $89(6)$ & 0.6 & 2 \\
\hline Endosulfan I (b) & - & $89(9)$ & 8 & 24 \\
\hline$p, p^{\prime}-\mathrm{DDE}^{(\mathrm{b})}$ & $87(11)$ & $82(4)$ & 0.6 & 2 \\
\hline Buprofezin (c) & - & $120(11)$ & 15 & 45 \\
\hline
\end{tabular}


Table 4 (continued).

\begin{tabular}{|c|c|c|c|c|}
\hline \multirow{2}{*}{ Compounds } & \multicolumn{2}{|c|}{ Fortification levels $(\mu \mathrm{g} / \mathrm{L})$} & \multirow{2}{*}{$\begin{array}{c}\text { LOD } \\
(\mu \mathrm{g} / \mathrm{L})\end{array}$} & \multirow{2}{*}{$\begin{array}{c}\mathrm{LOQ} \\
(\mu \mathrm{g} / \mathrm{L})\end{array}$} \\
\hline & 10 & 100 & & \\
\hline Dieldrin $^{(b)}$ & - & $85(10)$ & 4 & 12 \\
\hline Endrin ${ }^{(b)}$ & - & $93(9)$ & 5 & 15 \\
\hline Endosulfan II (b) & - & $107(9)$ & 10 & 30 \\
\hline$p, p^{\prime}-\mathrm{DDD}^{(\mathrm{b})}$ & $119(15)$ & $78(4)$ & 2 & 6 \\
\hline Ethion (a) & - & $88(7)$ & 5 & 15 \\
\hline Oxadixyl (c) & - & - & - & - \\
\hline Propiconazole I ${ }^{(\mathrm{c})}$ & - & $120(2)$ & 20 & 60 \\
\hline Propiconazole II (c) & - & $117(8)$ & 20 & 60 \\
\hline$p, p^{\prime}-\mathrm{DDT}^{(\mathrm{b})}$ & - & - & - & - \\
\hline Endosulfan sulfate ${ }^{(b)}$ & - & $108(12)$ & 10 & 30 \\
\hline Bifenthrin $^{(a)}$ & $83(8)$ & $72(8)$ & 1 & 3 \\
\hline Phosmet (a) & i. & i. & - & - \\
\hline Methoxychlor ${ }^{(b)}$ & - & - & - & - \\
\hline Tetradifon ${ }^{(c)}$ & - & $\underline{126(5)}$ & - & - \\
\hline Pyriproxyfen ${ }^{(c)}$ & - & $\underline{127(5)}$ & - & - \\
\hline Fenarimol (c) & - & $\underline{129(7)}$ & - & - \\
\hline Cypermethrin (a) & - & - & - & - \\
\hline Fenvalerate $^{(a)}$ & - & - & - & - \\
\hline
\end{tabular}

(a), (b), (c) indicates the internal standard used for each analyte: (a) terbutylazine- $\mathrm{D}_{5}$, (b) $p, p^{\prime}-\mathrm{DDE}-\mathrm{D}_{8}$, (c) hexachlorobenzene- ${ }^{13} \mathrm{C}_{6}$.

Underlined, not acceptable results. Detection (LOD) and quantification (LOQ) limits.

i., analyte not detected due to matrix interferences on the three analyte ions.

Linearity using matrix-matched standards was studied in the range 5$500 \mu \mathrm{g} / \mathrm{L}(n=3)$. Residuals were lower than $30 \%$ and correlation coefficients by linear curves were higher than 0.99 .

Accuracy and precision were evaluated by analyzing juice samples fortified at two levels (0.01 and $0.1 \mathrm{mg} / \mathrm{L}, n=6)$. Results of recoveries and RSD are shown in Table 4. Half of the compounds could not be validated at the lowest level due to insufficient sensitivity and/or matrix interferences, in agreement with previous works (Cherta et al. 2013), but most of them presented satisfactory recoveries (between 70 and $120 \%$ ) at $0.1 \mathrm{mg} / \mathrm{L}$, as well as adequate RSD values (lower than $15 \%$ ). LOQs 
ranged from 2 to $25 \mu \mathrm{g} / \mathrm{L}$ in most cases; exceptions were metribuzin, fenthion, buprofezin, endosulfan II, propiconazole and endosulfan sulfate, with LOQs between 30 and $60 \mu \mathrm{g} / \mathrm{L}$. Results are in accordance with recent literature (Nguyen et al. 2009; Furlani et al. 2011).

In order to test the applicability of the GC-MS method developed for the 56 studied pesticides, it was applied to real commercially obtained samples. Representative samples of four matrices were selected and analyzed, including mango-apple, pineapple, grapefruit and natural orange juices. Multi-fruit juice was used to perform calibration curves. As it corresponds to healthy commercial juices, no positive findings were detected in any of the samples.

\section{CONCLUSIONS}

Three different sample treatments based on QuEChERS, SPE and SPME have been applied and evaluated for the determination of pesticides in juice samples by fast GC-MS. A comparative study in terms of validation results, extraction efficacy and extraction times has been carried out for 15 representative pesticides in order to establish the best extraction conditions.

Most compounds presented a similar behavior in terms of recoveries and RSD. However, SPME resulted in the most sensitive approach allowing to reach better LOQs (up to 200 times lower) in comparison with QuEChERS and SPE. On the other hand, more matrix interferences were observed after injecting the SPE extracts, leading to poorer $Q / q$ ratio accomplishment that made identification of compounds in samples more problematic. Thus, SPE without additional cleanup seemed less adequate for complex matrices. Better results were obtained for the other two methodologies due to the cleanup step included in QuEChERS and the higher sensitivity achieved with SPME. As regards extraction times, SPME was the most time-consuming procedure and involved the longest chromatographic run time since an additional $5 \mathrm{~min}$ of desorption step in the injector was necessary. On the contrary, 
QuEChERS led to the highest sample throughput, making feasible the analysis of around 30 samples in 1 day.

QuEChERS was considered the most appropriate sample treatment for juice samples, although SPME allowed reaching lower quantification limits. The QuEChERS procedure in combination with fast GC-MS was extended to the residue determination of 56 pesticides in multi-fruit samples, with acceptable results for the wide majority of compounds. Analysis of fruit juice samples of apple-mango, pineapple, grapefruit and orange revealed that any of the pesticides investigated were present at levels above the LOD, all well below the MRLs.

\section{Acknowledgments}

This work has been developed under the financial support of Bancaixa (P11B2009-25 and P1-1B2010-23). The authors are very grateful to Izasa S.A. for providing the chromatographic system Shimadzu QP2010 Plus and acknowledge the financial support of Generalitat Valenciana, as research group of excellence PROMETEO/2009/054. The authors wish to thank Teknokroma for providing the 20-m GC column SAPIENS 5-MS. L. Cherta is very grateful to University Jaume I for his pre-doctoral grant.

\section{References}

Ai J (1997) Anal Chem 69:1230

Anastassiades M, Lehotay SJ, Štajnbaher D, Schenck FJ (2003) J AOAC Int 86:412

Albero B, Sánchez-Brunete C, Tadeo JL (2005) Talanta 66:917

Beltran J, Lopez FJ, Cepria O, Hernandez F (1998) J Chromatogr A 808:257

Beltran J, López FJ, Hernández F (2000) J Chromatogr A 885:389

Beltran J, Peruga A, Pitarch E, López FJ, Hernández F (2003) Anal Bioanal Chem $376: 502$ 
Beltran J, Pitarch E, Egea S, López FJ, Hernández F (2001) Chromatographia 54:757

Boyd-Boland AA, Pawliszyn JB (1995) J Chromatogr A 704:163

Burchat CS, Ripley BD, Leishman PD, Ritcey GM, Kakuda Y, Stephenson GR (1998)

Food Addit Contam 15:61

Cervera MI, Beltran J, Lopez FJ, Hernandez F (2011) Anal Chim Acta 704:87

Cieślik E, Sadowska-Rociek A, Ruiz JMM, Surma-Zadora M (2011) Food Chem $125: 773$

Cherta L, Beltran J, López FJ, Hernández F (2013) Food Anal Meth 6:1170

Cherta L, Beltran J, Portolés T, Hernández F (2012) Anal Bioanal Chem 402:2301

Cortés-Aguado S, Sánchez-Morito N, Arrebola FJ, Frenich AG, Vidal JLM (2008)

Food Chem 107:1314

Dai R, Ren X, He X, Huo Y (2011) Bull Environ Contam Toxicol 86:559

Dallüge J, Hankemeier T, Vreuls RJJ, Brinkman UAT (1999) J Chromatogr A 830:377

Dömötörová M, Matisová E (2008) J Chromatogr A 1207:1

European Commission (2008) Regulation (EC) No. 299/2008

European Commission Decision (2002) European Commission Decision 2002/657/EC. Official Journal of the European Community. 21 Aug 2002

Farajzadeh MA, Hatami M (2004) Chromatographia 59:259

Fidalgo-Used N, Montes-Bayón M, Blanco-González E, Sanz-Medel A (2006) J Anal At Spectrom 21:876

Furlani RPZ, Marcilio KM, Leme FM, Tfouni SAV (2011) Food Chem 126:1283

Fuster S, Beltran J, López FJ, Hernández F (2005) J Sep Sci 28:98

Hernández F, Pitarch E, Beltran J, López FJ (2002) J Chromatogr B Biomed Anal Technol Biomed Life Sc 769:65

Jiang Y, Li X, Xu J, Pan C, Zhang J, Niu W (2009) Food Addit Contam Part A Chem Anal Control Expo Risk Assess 26:859

Kataoka H, Lord HL, Pawliszyn J (2000) J Chromatogr A 880:35 
Kirchner M, Matisová E, Hrouzková S, De Zeeuw J (2005) J Chromatogr A 1090:126

Kolberg DI, Prestes OD, Adaime MB, Zanella R (2011) Food Chem 125:1436

Lehotay SJ, Maštovská K, Lightfield AR (2005) J AOAC Int 88:615

López FJ, Pitarch E, Egea S, Beltran J, Hernández F (2001) Anal Chim Acta 433:217

Magdic S, Boyd-Boland A, Jinno K, Pawliszyn JB (1996) J Chromatogr A 736:219

Marín JM, Gracia-Lor E, Sancho JV, López FJ, Hernández F (2009) J Chromatogr A 1216:1410

Mezcua M, Martínez-Uroz MA, Wylie PL, Fernández-Alba AR (2009) J AOAC Int 92:1790

Mladenova R, Shtereva D (2009) Food Addit Contam Part A Chem Anal Control Expo Risk Assess 26:854

Natangelo M, Tavazzi S, Benfenati E (2002) Anal Lett 35:327

Nguyen TD, Yun MY, Lee GH (2009) J Agric Food Chem 57:10095

Pang G, Fan C, Liu Y, Cao Y, Zhang J, Fu B et al (2006) Food Addit Contam 23:777

Park J, Choi J, Abd El-Aty AM, Kim BM, Oh J, Do J et al (2011) Food Chem 128:241

Patyal SK, Lakhanpal AK, Nath A, Sharma PC (2004) J Food Sci Technol 41:316

Payá P, Anastassiades M, MacK D, Sigalova I, Tasdelen B, Oliva J et al (2007) Anal Bioanal Chem 389:1697

Picó Y, Fernández M, Ruiz MJ, Font G (2007) J Biochem Biophys Methods 70:117

Picó Y, Kozmutza C (2007) Anal Bioanal Chem 389:1805

Piedra L, Tejedor A, Hernando MD, Aguera A, Barcelo D, Fernández-Alba A (2000)

Chromatographia 52:631

Pitarch E, Medina C, Portolés T, López FJ, Hernández F (2007) Anal Chim Acta 583:246

Sabik H, Jeannot R, Rondeau B (2000) J Chromatogr A 885:217

Schurek J, Portolés T, Hajslova J, Riddellova K, Hernández F (2008) Anal Chim Acta 611:163

Sen NP, Seaman SW, Page BD (1997) J Chromatogr A 788:131 
Serrano E, Beltrán J, Hernández F (2009) J Chromatogr A 1216:127

Simplício AL, Vilas Boas L (1999) J Chromatogr A 833:35

Xue N, Zhang D, Xu X (2006) Water Res 40:183

Zambonin CG, Cilenti A, Palmisano F (2002) J Chromatogr A 967:255 